\title{
Detecção e Epidemiologia da Podridão Branca da Maçã*
}

\author{
Rosa M. Valdebenito-Sanhueza' ${ }^{1}$, Valmir Duarte², Lílian Amorim³ \& Miguel D. M. Porto² \\ ${ }^{1}$ Embrapa Uva e Vinho, Cx. Postal 130, CEP 95700-000, Bento Gonçalves, RS, e-mail: rosa@ cnpuv.embrapa.br; \\ ${ }^{2}$ Universidade Federal de Rio Grande do Sul, Cx. Postal 15100, Porto Alegre, RS; ${ }^{3}$ Escola Superior de Agricultura \\ "Luiz de Queiroz", CEP 13418-900, Piracicaba, SP
}

(Aceito para publicação em 20/12/2004)

Autor para correspondência: Rosa M. Valdebenito-Sanhueza

VALDEBENITO-SANHUEZA, R.M., DUARTE, V., AMORIM, L. \& PORTO, M.D.M. Detecção e epidemiologia da podridão branca da maçã. Fitopatologia brasileira 30:217-223. 2005.

RESUMO

Embora a 'Podridão branca' causada por Botryosphaeria dothidea seja uma das principais doenças de verão da macieira (Malus domestica), há pouca informação no Brasil sobre o patógeno e a doença. Este trabalho objetivou definir métodos para a produção de inóculo, para avaliação da patogenicidade de $B$. dothidea em maçãs sem ferimentos e para desinfestação das maçãs visando a detecção de infecções quiescentes. Caracterizou-se, também, o progresso temporal e o padrão espacial de frutos e de árvores doentes em pomar comercial. A produção de inóculo em batata-dextrose-ágar com papel de filtro e a inoculação de maçãs submetidas previamente a dois dias de câmara úmida, com conídios aderidos em papel toalha, foram eficazes na produção de inóculo e o desenvolvimento da doença, respectivamente. O melhor método de detecção de infecção latente foi a desinfestação das maçãs com uma mistura de $\mathrm{NaOCl} 1,25 \%$ de cloro ativo e álcool 9,6 $6^{\circ}$ GL por 2 min. A produção de inóculo de $B$. dothidea nos ramos de poda foi observado em meses diferentes em cada ciclo. No ciclo 1999, verificou-se infecção das maçãs por $B$. dothidea, mesmo com proteção química do pomar e não houve diferença na incidência entre frutas oriundas de diferentes posições na árvore. A análise do padrão de distribuição da doença mostrou agregação distinta das árvores doentes e agregação baixa, dos frutos sintomáticos em cada macieira.

Palavras-chave adicionais: macieira, fruteiras temperadas, Botryosphaeria dothidea.

\begin{abstract}
Detection and epidemiology of white rot on apples

Although white rot caused by Botryosphaeria dothidea is one of the most important diseases of apple (Malus domestica) in Brazil during rainy summer seasons, local information on the disease and pathogen is scarce. The aim of this research was to define methods of inoculating $B$. dothidea on apple fruits without wounding them, to detect latent infection and to analyze the temporal and spatial patterns of the disease in a commercial orchard. The best results of inoculum production were obtained on PDA covered with filter paper. The higheest apple infection rates were obtained after two days in a humid chamber before inoculation with a conidial suspension carried by a piece of paper. Latent infection was better detected when infected fruits were disinfested with $\mathrm{NaOCl}, 1.25 \%$ of active chlorine and $9.6^{\circ} \mathrm{GL}$ of ethylic alcohol for 2 min. Production of $B$. dothidea on pruning stems occurred in different periods of each season. The disease distribution in a fungicide treated orchard showed clear aggregation of diseased plants but slight aggregation of fruits inside the plant.
\end{abstract}

Additional keywords: apple plants, temperate fruit crops, Botryosphaeria dothidea.

\section{INTRODUÇÃO}

Atualmente, cerca de 32 mil ha de macieira (Malus domestica Borkh.) são cultivados no Brasil. Entre as doenças desta cultura, a podridão branca (Botryosphaeria dothidea (Moug.) Ces. \& De Not. (Fusicoccum aesculi Corda) sin. B. berengeriana) é uma das de mais difícil controle, pois apesar de a infecção ocorrer em frutos jovens, os sintomas tornamse evidentes à medida que se aproxima a colheita. Nos anos

*Pesquisa desenvolvida com suporte parcial do CNPq, da FAPERGS, e da ABPM. com verões chuvosos e temperaturas amenas, os danos por podridão branca comprometem a produção de maçãs no Brasil (Petri, 1998). Nos Estados Unidos da América citam-se perdas importantes causadas pela podridão branca, as quais podem atingir até $100 \%$ dos frutos (Shear et al., 1925; Shay \& Sitterly, 1954; Brown \& Britton, 1986). Segundo Jones \& Aldwinckle (1990), o patógeno sobrevive nos cancros dos ramos e tronco e, a partir deles na primavera, inicia a liberação de ascósporos e/ou conídios, os quais infetam os frutos em desenvolvimento (Sutton, 1981; Sutton \& Boyne, 1983). A penetração é direta, necessitando da presença de água livre; 
a temperatura ótima para germinação é de 28 a $32^{\circ} \mathrm{C}$. Um modelo de previsão de ocorrência da podridão branca foi desenvolvido com o objetivo de racionalizar o uso de fungicidas (Parker \& Sutton, 1993a), faltando, contudo, sua validação em condições de campo. Há informações contraditórias na literatura quanto à época de ocorrência das infecções. Assim, Kohn \& Hendrix (1983) postularam que esse processo ocorre somente nos frutos que apresentam mais de $10,5^{\circ}$ Brix de sólidos solúveis totais, mas Parker \& Sutton (1993b) demonstraram que a infecção pode ocorrer durante todo o ciclo da cultura.

$\mathrm{O}$ patógeno pode infetar frutos imaturos intactos e permanecer na forma quiescente até o início da maturação. No entanto, o nível de infecção é maior em maçãs que apresentam rachaduras ou irregularidades na cutícula causadas por 'russeting', escaldadura pelo sol ou danos por toxicidade de agroquímicos (Jones \& Aldwinckle, 1990).

As infecções latentes causadas por $B$. dothidea são controladas com tratamento das maçãs, antes da armazenagem, com fungicidas protetores e benzimidazóis aplicados durante o ciclo vegetativo. No entanto, há restrições para aplicações desses produtos em pós-colheita em frutos destinados ao consumo in natura, por isso recomenda-se a sua substituição por outros métodos de controle (Pennock \& Maldonado, 1962).

A estimativa correta da incidência de infecções latentes da podridão branca em maçãs, em frutos amostrados no período de pré-colheita, permite avaliar a eficiência dos tratamentos e a previsão das perdas de frutos na comercialização (Biggs, 1995). A aceleração da maturação dos frutos pela manutenção em temperatura entre 22 e 26 ${ }^{\circ} \mathrm{C}$, com alta umidade, ou pelo uso de paraquat, pode facilitar a manifestação das lesões. Estas técnicas têm sido usadas na detecção de infecções latentes de Botryosphaeria sp., Glomerella sp. e Colletotrichum sp. em frutos (Biggs, 1995). A toxicidade do paraquat tem limitado a recomendação do uso desta técnica para produtores.

No Brasil, os estudos têm-se limitado a registros de ocorrência (Melzer \& Berton, 1886; Boneti et al., 1999), com poucas informações sobre as características do patógeno e nenhuma sobre a epidemiologia da podridão branca. Assim, as medidas de controle têm-se resumido à aplicação preventiva de fungicidas, de alto custo econômico e ambiental e com resultados insatisfatórios.

Este trabalho apresenta um método para a detecção precoce das lesões latentes nos frutos de macieira e analisa o progresso temporal e o padrão espacial de frutos doentes em um pomar comercial.

\section{MATERIAL E MÉTODOS}

\section{Métodos para a produção de inóculo}

Foram comparados os efeitos na esporulação do patógeno de dois meios de cultura cobertos com celofane ou com papel de filtro. Fragmentos de maçãs doentes, previamente inoculadas com o isolado de $B$. dothidea $\mathrm{BDCax}$ da coleção da Estação Experimental de Vacaria, da Embrapa Uva e Vinho, foram transferidos para placas com os meios de cultura batata-dextroxe-ágar (BDA) e ágar-aveia, ambos com $2 \%$ de ágar, tendo as superfícies cobertas com papel filtro ou celofane. As culturas foram incubadas por dez dias a $24^{\circ} \mathrm{C}$. O papel filtro e o celofane foram, então, cortados em pequenos segmentos, homogeneizados em água destilada, a suspensão filtrada através de gaze e a quantidade de conídios determinada com hemacitômetro. Cada tratamento teve cinco repetições representadas por uma placa.

\section{Métodos de inoculação das maçãs com Botryosphaeria dothidea}

Maçãs 'Fuji' foram lavadas com detergente, secas e inoculadas com suspensões de conídios de $B$. dothidea $\left(1 \times 10^{6}\right.$ conídios $/ \mathrm{ml}$ ). Foram comparados os métodos de aplicação do inoculo por aspersão e com o uso de papel toalha. O último, adaptado de Parker \& Sutton (1993 a), consistiu na colocação de uma gota de $5 \mu$ l da suspensão na região equatorial de cada fruto e da cobertura com um segmento de papel toalha $(0,5 \mathrm{x}$ $0,5 \mathrm{~cm}$ ) fixado com fita adesiva de celulose. Os frutos foram incubados a 26 ou $30^{\circ} \mathrm{C}$. As testemunhas foram tratadas com água destilada esterilizada. $\mathrm{O}$ delineamento foi inteiramente casualizado com três repetições, cada uma constituída por seis frutos. O número de lesões por fruto foi registrado.

Adicionalmente, verificou-se o efeito de períodos de câmara úmida prévia no estabelecimento da infecção. Maçãs foram submetidas a períodos de câmara úmida de zero, dois e cinco dias a $26^{\circ} \mathrm{C}$ antes de serem inoculadas através do método de papel toalha e utilizando-se fita adesiva sintética. Os frutos foram mantidos em ambiente com igual temperatura e avaliados após 12 e 18 dias. Utilizou-se delineamento experimental inteiramente casualizado com quatro repetições, com três frutos cada. O numero de frutos com sintomas foi registrado.

Para determinar a germinação de conídios de $B$. dothidea em água destilada sem nutrientes adicionais, foram preparadas quatro suspensões de conídios produzidos em papel de filtro $\left(1.10^{6} \mathrm{con} / \mathrm{ml}\right)$ e estas foram incubadas por cinco dias a $24{ }^{\circ} \mathrm{C}$. Após este período foi determinada a quantidade de conídios germinados em três campos de cada suspensão.

\section{Métodos de desinfestação de maçãs}

Foram conduzidos dois experimentos para definir o método que melhor detectasse a presença de infecções latentes em maçãs 'Fuji' de calibre 165, inoculadas com $B$. dothidea usando o método de papel toalha e incubadas por $72 \mathrm{~h}$ a $30^{\circ} \mathrm{C}$. No primeiro, os frutos foram imersos durante 3 min nas seguintes soluções: a) álcool etílico hidratado $67,2{ }^{\circ} \mathrm{GL}$ e hipoclorito de sódio, $1,25 \%$ de cloro ativo, consecutivamente; b) paraquat $0,01 \%$; c) uréia, $5 \%$; d) ethrel, $0,01 \%$.

No segundo experimento, maçãs com inoculação feita conforme descrita no ensaio anterior, foram imersas nas seguintes soluções: a) hipoclorito de sódio, $1,5 \%$ de cloro ativo, e álcool etílico hidratado $67,2^{\circ} \mathrm{GL}$, consecutivamente, por 1, 2 e $3 \mathrm{~min}$; b) hipoclorito de sódio, 1,25\% de cloro ativo com álcool 9,6 ${ }^{\circ} \mathrm{GL}$ por $1 \mathrm{~min}$; c) hipoclorito de sódio, 2,5\% 
de cloro ativo; d) álcool etílico hidratado $67,2^{\circ} \mathrm{GL}$; e) ethrel, $0,01 \%$; f) paraquat, $0,01 \%$; g) uréia, $5 \%$. Os experimentos foram conduzidos com delineamento inteiramente casualizado com três repetições, cada uma constituída por oito frutos. O número de lesões por fruto foi registrado. Os experimentos foram repetidos uma vez.

\section{Determinação da incidência em macieiras com proteção química}

Os experimentos foram instalados em um pomar da empresa Schio (Vacaria, RS), com histórico de alta incidência de podridão branca e conduzidos durante os ciclos de 19981999 e 2000-2001. Quatro caixas, com ramos oriundos da poda da macieira infetados com $B$. dothidea, foram distribuídas sobre o solo, no pomar, para assegurar a presença de inóculo no local e junto a cada uma delas foram colocados dois coletores de esporos na altura de $80 \mathrm{~cm}$. Cada coletor era composto de uma lâmina de vidro vaselinada. Ao redor dos coletores, 40 plantas foram marcadas e avaliadas. De fevereiro a abril as plantas foram pulverizadas com o fungicida captan, na dose de 125 g.i.a/100 1 de água, em intervalos de 15 dias ou quando acumulados $80 \mathrm{~mm}$ de chuva. Antes de cada pulverização, as lâminas foram avaliadas. No mesmo dia da avaliação das lâminas, coletaram-se cinco frutos do terço inferior, cinco do terço médio e cinco do terço superior de cada uma das 40 plantas localizadas ao redor das caixas. Os frutos foram desinfestados por imersão em solução de álcool $67,2^{\circ} \mathrm{GL}$ por 3 min e em hipoclorito de sódio $1,25 \%$, também por $3 \mathrm{~min}$. Em seguida, os frutos foram incubados por 12 dias a $26^{\circ} \mathrm{C}$. Após esse período registrou-se o número de frutos com podridão branca. Foram realizadas cinco avaliações entre fevereiro e abril. Calculou-se a área sob a curva de progresso da incidência da doença (ASCPD) para cada um dos terços de cada planta e os valores foram comparados por meio de análise de variância.

\section{Padrão espacial da podridão branca}

Para a determinação do padrão espacial de distribuição da doença coletou-se, em uma área próxima deste pomar, cinco frutos do terço inferior, cinco do terço médio e cinco do superior de cada planta, de 17 grupos constituídos por seis plantas. Os frutos foram desinfestados, incubados e avaliados como citado anteriormente. Foram feitas duas coletas em abril. A partir destes dados foi calculado o índice de dispersão $(D)$ para dados binários considerando duas unidades amostrais distintas: a planta doente no campo e os frutos doentes na planta. Na análise da distribuição das plantas doentes, em cada data de avaliação, $D=s^{2} /[p(1-p) / n]$, onde $s^{2}$ é a variância observada $\left(V_{\text {obs }}\right)$ entre quadrats e $p(1-p) / n$ é a variância da distribuição binomial $\left(V_{\text {bin }}\right)$, na qual $n$ representa o número de plantas por quadrat $\mathrm{e} p$, a incidência de plantas doentes (Madden \& Hughes, 1995). Aos valores de $D$ para cada planta foi aplicado o teste do $\chi^{2}$ (qui-quadrado) para verificar se o valor calculado foi maior ou igual a 1 ao nível de significância de $5 \%$. Valores de $D$ significativamente iguais a 1 indicam que as plantas com sintomas estão distribuídas aleatoriamente no campo. Valores de $D$ significativamente maiores que 1 indicam que as plantas com sintomas estão agregadas (Madden \& Hughes, 1995).

A mesma análise foi feita considerando-se como unidade amostral os frutos doentes de cada grupo de seis plantas. Nesse caso, calculou-se um índice de dispersão para cada um dos 17 grupos de plantas, nas duas avaliações. Em seguida calculou-se a forma binária da lei de Taylor (Hughes \& Madden, 1992), que relaciona a variância observada $\left(V_{\mathrm{obs}}\right)$ e a variância binomial esperada $\left(V_{\text {bin }}\right)$ para uma distribuição ao acaso de dados binários. Nesse caso, $\log \left(V_{\text {obs }}\right)=\log (A)+b$ $\log \left(V_{\text {bin }}\right)$, onde $A$ e $b$ são parâmetros. Uma regressão linear, calculada pelo método de quadrados mínimos, foi aplicada conjuntamente aos dados obtidos nas duas datas de avaliação, considerando a variância binomial a variável independente e a variância observada, a variável dependente. A significância da regressão foi determinada pelo teste $\mathrm{F}$ e adequação do ajuste foi avaliada pelo coeficiente de determinação $\left(R^{2}\right)$ e pela análise da distribuição de resíduos. Se a distribuição dos frutos doentes for ao acaso, $b=A=1$. Quando $b=1$ e $A>1$, há um nível constante de agregação para todos os valores de incidência. Quando $b>1$ o nível de agregação aumenta com o aumento da incidência (Madden \& Hughes, 1995). A igualdade dos parâmetros $A$ e $b$ a 1 foi testada pelo teste $t$ (Campbell \& Madden, 1990).

\section{Sobrevivência e detecção de Botryosphaeria dothidea nos ramos de macieiras no pomar}

No mês de julho, logo após a poda, três conjuntos de cinco segmentos de ramos de macieiras foram colocados no solo, na região da projeção da copa das plantas da cv Fuji em Vacaria, cada um com diâmetros de 0,5, 1,0 e 1,5 cm, dispostos em tela plástica com malha de $1,5 \mathrm{~cm}$. Os ramos foram mantidos no campo durante os ciclos vegetativos de $1998 \mathrm{e}$ 2000, e examinados quinzenalmente para detectar a presença de estruturas do patógeno.

\section{RESULTADOS E DISCUSSÃO}

\section{Métodos para a produção de inóculo}

Dos métodos comparados o mais eficaz para produção de inóculo do patógeno foi o BDA com papel de filtro, produzindo-se a média de $1,3 \times 10^{6}$ conídios por placa após dez dias de incubação e observando-se neste caso, menor quantidade de micélio e maior número de picnídios, sendo facilitada a separação dos conídios das outras estruturas do fungo e do meio de cultura. O BDA com celofane, o meio de aveia com papel e celofane produziram $4,5 \times 10^{5}, 4,08 \times 10^{5}$ e 2,8 × $10^{4}$ conídios por placa, respectivamente.

A produção de inóculo de $B$. dothidea tem sido feita em meios diversos entre os que se inclui o BDA (Fenner, 1925; Lewis, 1956; Hutton \& Leigh,1958). O desenvolvimento dos picnídios ocorre nesta condição, no entanto, o processo pode demorar três semanas e a remoção dos conídios é dificultada pela necessidade de separar o meio de cultura das estruturas do fungo (Brown \& Hendrix, 1981). Nenhuma citação prévia 
foi encontrada sobre a produção de inóculo deste fungo em meio de cultura coberto por papel ou membranas.

\section{Métodos de inoculação das maçãs com Botryosphaeria dothidea}

Na comparação de métodos de inoculação com incubação em duas condições de temperatura (Tabela 1), o método de papel toalha foi o mais eficaz para assegurar o desenvolvimento da doença nas duas temperaturas avaliadas. Porém, quando a fruta foi incubada a $30{ }^{\circ} \mathrm{C}$, observou-se maior incidência e severidade da doença, fato que coincidiu com as condições citadas previamente (Lewis \& Shay, 1953; Lewis, 1956).

$\mathrm{Na}$ avaliação da influência de períodos de câmara úmida no tratamento de maçãs antes da infecção, constatouse que nos dois períodos de avaliação a maior incidência da doença ocorreu quando foi utilizado um período de dois dias de câmara úmida (Tabela 2). Na avaliação das suspensões de conídios verificou-se a ausência de germinação em todas as amostras observadas. De acordo aos resultados obtidos devese supor que os conídios de $B$. dothidea são dependentes de nutrientes exógenos para germinar sendo provável que o estímulo do período de câmara úmida ocorra pela acumulação de exsudatos da fruta nessa condição. Este fato foi constatado em outros patógenos, como Botrytis cinerea e Glomerella cingulata (Stonem.) Spauld \& Screnk. [Colletotrichum gloeosporioides (Penz.) Penz. \& Sacc] (Bailey et al., 1992), mas ainda não foi relatado para $B$.

TABELA 1 - Incidência e severidade de podridão branca em frutos de macieira (Malus domestica) 'Fuji' inoculados com Botryosphaeria dothidea através de dois métodos sob duas temperaturas. Vacaria, RS

\begin{tabular}{|c|c|c|c|c|}
\hline \multirow[b]{3}{*}{ Método } & \multicolumn{4}{|c|}{ Temperatura } \\
\hline & \multicolumn{2}{|c|}{$26^{\circ} \mathrm{C}$} & \multicolumn{2}{|c|}{$30^{\circ} \mathrm{C}$} \\
\hline & $\begin{array}{l}\text { Frutos com } \\
\text { podridãol } \\
\text { seis frutos } \\
\end{array}$ & $\begin{array}{c}\text { Lesões/ } \\
\text { Fruto }\end{array}$ & $\begin{array}{l}\text { Frutos com } \\
\text { podridão / } \\
\text { seis frutos } \\
\end{array}$ & $\begin{array}{c}\text { Lesões/ } \\
\text { Fruto }\end{array}$ \\
\hline Aspersão & $1, \mathbf{0} \mathbf{a}^{1}$ & $1,6 \mathbf{a}$ & $2,0 \mathrm{a}$ & $4,0 \mathrm{a}$ \\
\hline Papel toalha & $2,6 \mathrm{~b}$ & $3,7 \mathbf{b}$ & $5,6 \mathrm{~b}$ & $19,0 \mathrm{~b}$ \\
\hline
\end{tabular}

${ }^{1}$ Médias de três repetições, cada uma com seis maçãs. Dados seguidos por letras iguais não diferem entre si (Duncan, $p<0,05$ )

TABELA 2 - Número de frutos de macieira (Malus domestica), mantidos em câmara úmida durante diferentes períodos antes da inoculação com Botryosphaeria dothidea, com podridão branca. Vacaria, RS. 1999

\begin{tabular}{|c|c|c|}
\hline \multirow{2}{*}{$\begin{array}{l}\text { Número de dias } \\
\text { em câmara } \\
\text { úmida a } 26^{\circ} \mathrm{C} \\
\end{array}$} & \multicolumn{2}{|c|}{$\begin{array}{c}\begin{array}{c}\text { Avaliação do número de frutos com } \\
\text { sintomas* }\end{array} \\
\end{array}$} \\
\hline & Apás 12 dias & Após 18 dias \\
\hline Zero & 0,0 & 0,25 \\
\hline 2 & 0,25 & 0,4 \\
\hline 5 & 0,0 & 0,0 \\
\hline
\end{tabular}

*Médias de quatro repetições, cada uma com três maçãs. dothidea. O menor efeito do período de cinco dias de câmara úmida poderá ser devido à exaustão de nutrientes que microrganismos epífitos podem causar em frutos nestas condições (Fokkema, 1988).

Verificou-se menor incidência e severidade da doença no segundo ensaio de comparação de métodos de inoculação e a diferença deve ser atribuída à qualidade da fita adesiva utilizada. É provável que a permeabilidade aos gases da fita de celulose seja maior e por isto, será recomendável utilizar este tipo de fita adesiva na inoculação de $B$. dothidea nas maçãs.

A inoculação de frutos tem sido feita com micélio (Brown \& Britton,1986) ou conídios em frutos com ferimentos (Fenner, 1925; Fulkerson, 1960; Brown \& Britton, 1986). Parker \& Sutton (1993a), porém, utilizaram papel embebido em suspensão de conídios seguido da proteção individual das maçãs com papel alumínio. A incubação das maçãs inoculadas foi feita com temperaturas que variaram entre 24 e $30{ }^{\circ} \mathrm{C}$ (Lewis, 1956; Kohn \& Hendrix, 1983) quando utilizado o método de aspersão. Na inoculação por aspersão, os pesquisadores citados utilizaram conídios obtidos pela lavagem da superfície dos meios de cultura, método que deve ter suprido os nutrientes necessários para o inicio da infecção.

\section{Métodos de desinfestação de maçãs}

No primeiro ensaio as maçãs tratadas com paraquat e com ethrel escureceram e inviabilizaram a detecção do sintoma da doença. Nos frutos imersos em uréia 5\% e naqueles com imersão consecutiva por $3 \mathrm{~min}$ em hipoclorito de sódio e álcool, constatou-se 38\% de frutos com sintomas da doença na avaliação aos 12 dias. No segundo ensaio (Tabela 3), constataram-se, nos tratamentos com paraquat e, em menor grau, com a uréia, danos à epiderme dos frutos, fato que promoveu o surgimento de lesões que associaram a fitotoxicidade do produto à colonização dos tecidos pelo patógeno e conduziram posteriormente à decomposição total da maioria dos frutos, impedindo a determinação clara dos sintomas. O tratamento consecutivo dos frutos por $3 \mathrm{~min}$ com hipoclorito de sódio $1,25 \%$ e no álcool, $67,2{ }^{\circ} \mathrm{GL}$ proporcionou a colonização das maçãs inoculadas com o patógeno dez dias após a inoculação. Este tratamento, considerado padrão para desinfestação de frutos, apresentou eficácia semelhante ao de imersão das maçãs por 2 min em hipoclorito de sódio 1,25\% e álcool $9,6{ }^{\circ} \mathrm{GL}$ e no de álcool $67,2^{\circ} \mathrm{GL}$. A incidência da doença nos outros tratamentos avaliados não se diferenciou da testemunha sem tratamento. Dessa forma, sugere-se que para a detecção das infecções quiescentes da podridão branca das maçãs, no processo de desinfestação das maçãs, seja utilizada a mistura de hipoclorito de sódio com $1,25 \%$ de cloro ativo mais $9,6{ }^{\circ} \mathrm{GL}$ de álcool por $2 \mathrm{~min}$, pois, neste caso, é menor o tempo de preparo e da imersão dos frutos.

Os métodos comparados para a detecção de infecção latente foram baseados no relatado por Biggs (1995) que usou a estratégia de indução da morte das células da epiderme com o herbicida paraquat para favorecer a expressão da infecção e 
TABELA 3 - Incidência da podridão branca (Botryosphaeria dothidea) em maceira (Malus domestica) 'Fuji' inoculadas com o método de papel toalha e incubados por $72 \mathrm{~h}$ a $30{ }^{\circ} \mathrm{C}$, após diferentes tratamentos de desinfestação. Vacaria, RS. 1999

\begin{tabular}{|c|c|c|c|}
\hline Tratamento & Dose & $\begin{array}{c}\text { Período de } \\
\text { Imersão (min) }\end{array}$ & Número de lesões por fruto \\
\hline Paraquat & $0,01 \%$ & 2 & $8,0 \mathrm{a}^{1,2}$ \\
\hline Uréia & $5 \%$ & 2 & $5,2 \mathrm{ab}^{2}$ \\
\hline Álcool e hipoclorito de sódio & $9,6^{\circ} \mathrm{GL}+1,25 \%$ & 2 & $3,9 \mathrm{bc}$ \\
\hline Álcool & $67,2^{\circ} \mathrm{GL}$ & 2 & $3,0 \mathrm{bcd}$ \\
\hline Álcool e hipoclorito de sódio & $67,2{ }^{\circ} \mathrm{GL}$ e $1,25 \%$ & 3 & $2,6 \mathrm{bcd}$ \\
\hline Ethrel & $0,01 \%$ & 2 & $1,9 \mathrm{~cd}$ \\
\hline Testemunha inoculada e sem desinfestar & --- & ---- & $1,9 \mathrm{~cd}$ \\
\hline Hipoclorito de sódio & $2,5 \%$ & 2 & $1,8 \mathrm{~cd}$ \\
\hline Álcool e hipoclorito de sódio & $67,2^{\circ} \mathrm{GL}$ e $1,25 \%$ & 1 & $1,3 \mathrm{~cd}$ \\
\hline Testemunha (sem inoculação) & ---- & ------- & $0,6 \mathrm{~d}$ \\
\hline
\end{tabular}

${ }^{1}$ Três repetições cada uma constituída por oito frutos. Dados seguidos por letras iguais não deferem entre si (Duncan, $\mathrm{p}<0,05$ )

${ }^{2}$ Lesões que associaram a fitotoxicidade à colonização dos tecidos pelo patógeno.

o descrito por Parker \& Sutton (1993a) na desinfestação de maçãs para eliminar os propágulos presentes na superfície do fruto.

A proposta de avaliação do ethrel, por outro lado, visou estimular a produção de etileno nos frutos e, com isto, a
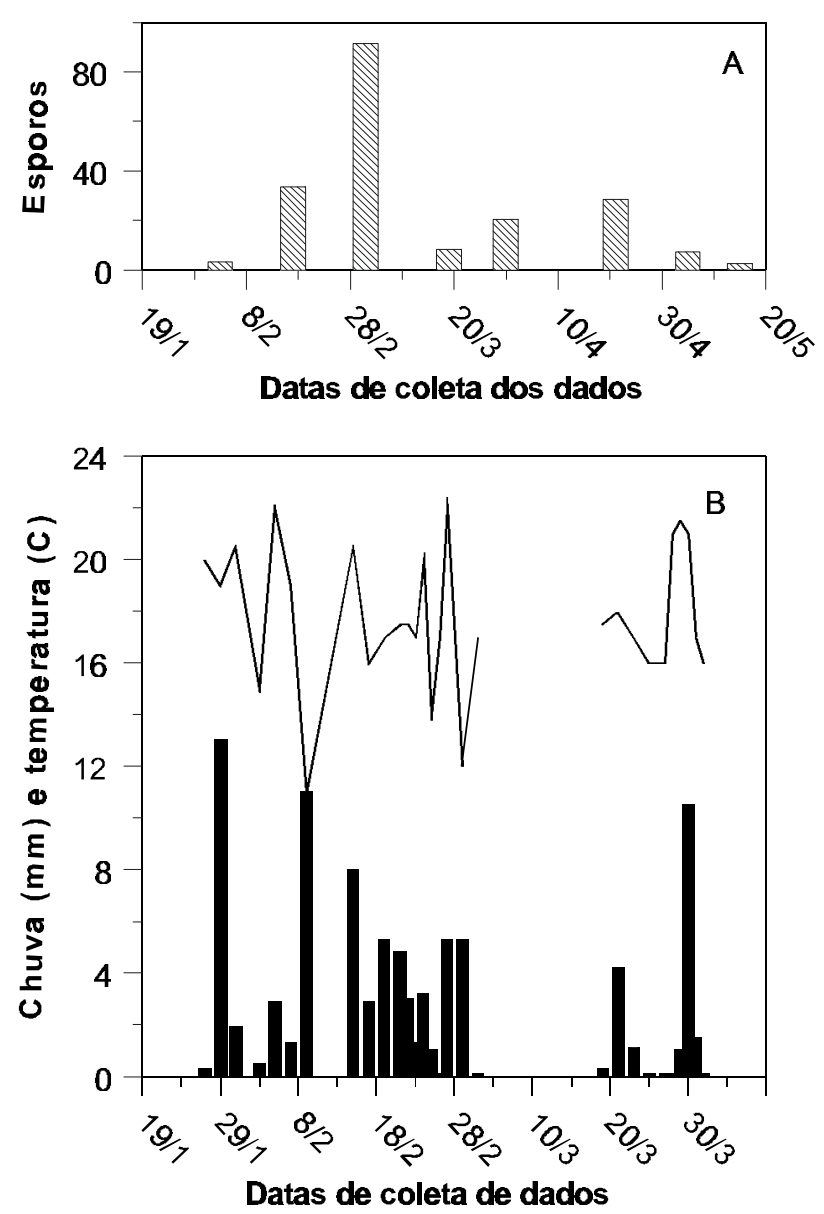

FIG. 1 - Número médio de esporos/lâmina de Botryosphaeria dothidea (A), detectados através de coletores situados no pomar de macieira (Malus domestica) da cv. Fuji, entre janeiro e maio, e temperatura média (linha) e chuva (barras) de janeiro a março de 1999 (B). ativação das lesões (Prusky et al., 1996) efeito citado em abacates (Persea americana Mill) com infecções latentes de C. gloeosporioides e, no caso da uréia, foi proposto avaliar um tratamento que causasse um dano celular na epiderme semelhante ao do paraquat e que não tivesse o risco toxicológico deste produto.

\section{Determinação da incidência da podridão branca em macieiras com proteção química}

No ciclo 1998-1999, a doença foi constatada somente em três frutos $(0,001 \%)$ apesar de haver sido registrada a presença de esporos de $B$. dothidea durante o período (Figura 1A). É provável que isto tenha ocorrido pela ausência de condições meteorológicas favoráveis para o inicio da infecção visto que nos períodos de molhamento, a temperatura não atingiu $20^{\circ} \mathrm{C}$ (Figura 1B) e nos trabalhos desenvolvidos por Parker \& Sutton, 1993a em condições controladas, a maior incidência foi constatada sob condições de temperaturas altas (Parker \& Sutton, 1993a). No ciclo 2000-2001, porém, a doença se manifestou em intensidade alta. A presença de inóculo no pomar no início do ano (Figura 2A) e a temperatura média alta, superior a $20^{\circ} \mathrm{C}$, na maior parte do período de avaliação, permitiu a infecção de $B$. dothidea, que cresceu mesmo com a proteção do pomar (Figura 2B). Após a primeira constatação(18/02/2001), a temperatura média se manteve no geral acima de $20{ }^{\circ} \mathrm{C}$, com maior frequiência ao redor de $22^{\circ} \mathrm{C}$, com vários períodos de chuvas em dias consecutivos e/ou de chuvas maiores de $20 \mathrm{~mm}$. Estas condições devem ter contribuído para a perda da proteção conferida pelo captan mais adesivo e para o aumento gradual da incidência da doença no período. De acordo com as curvas médias de progresso da doença para cada altura de amostragem na árvore (Figura 2B) não houve diferença significativa entre as incidências de cada terço da árvore. A análise de variância dos dados de ASCPD mostrou médias semelhantes $(\mathrm{P}<0,05)$ nas incidências observadas nas diferentes alturas da planta. Isso indica que os ascósporos são os principais responsáveis pela infecção, já que são dispersos pelo ar. Caso os conídios representassem papel importante no progresso da doença, haveria maior número 

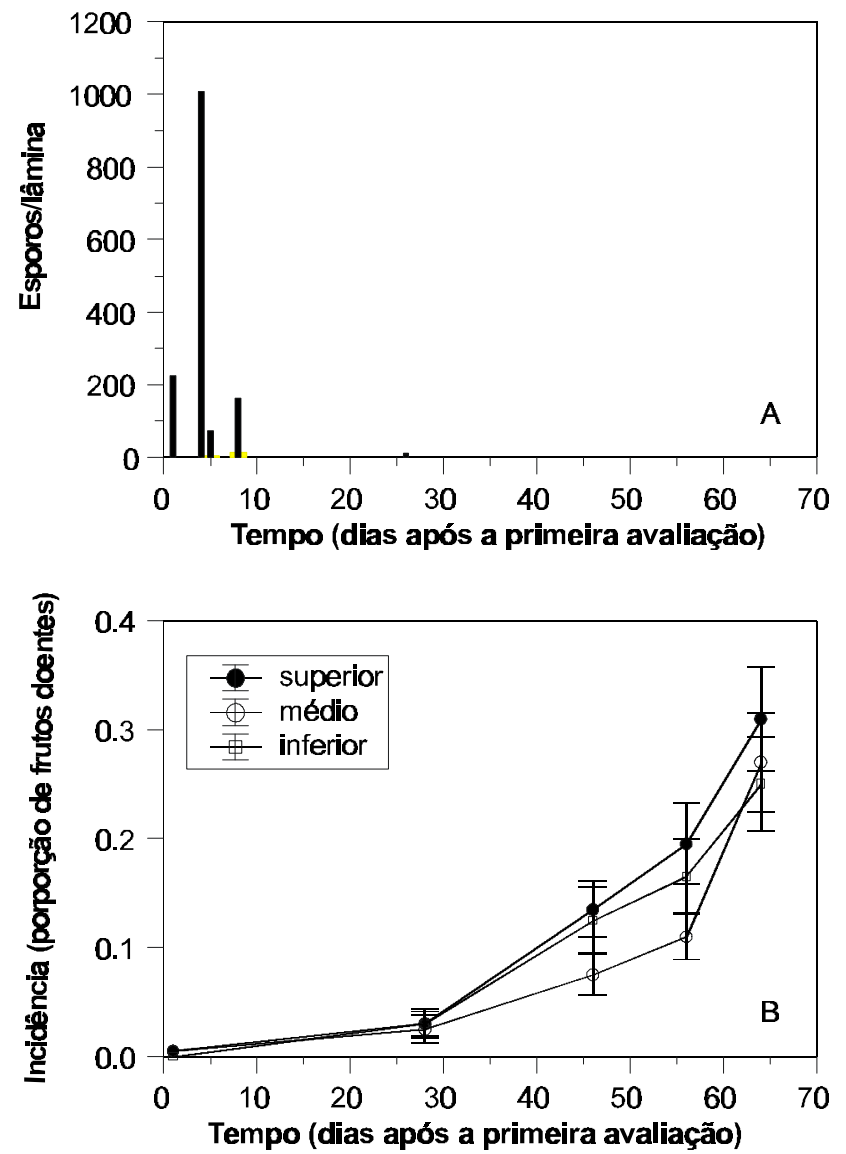

FIG. 2 - Número total de esporos do Botryphaeria dothidea capturados nas lâminas (A) e curvas de progresso da incidência de frutos de macieira (Malus domestica) doentes em cada terço amostrado da árvore (B) no período de janeiro a abril de 2001.Primeira avaliação em 28/02/2001.

de frutos infetados nos terços médio e inferior, uma vez que esses esporos são produzidos nos ramos e transportados pela água de chuva. Conídios dispersos por respingos de chuva tendem a acumular-se nas partes mais baixas das plantas.

\section{Padrão espacial da doença}

A análise do padrão de distribuição da doença neste pomar, feita a partir de dados coletados em 17 grupos com seis plantas, em duas datas, mostrou que as árvores doentes estavam agregadas. Os valores de $D$ foram iguais a 2,28 e 2,05 , respectivamente para a primeira e a segunda avaliações, ambos significativamente maiores que 1. A análise de distribuição de frutos doentes nas árvores, sumarizada pela regressão entre o logaritmo da variância binomial e o logaritmo da variância observada (Figura 3), mostra que os frutos estão ligeiramente agregados nas árvores. Apesar do valor da intersecção e do coeficiente angular da reta diferirem de 1 , em muitos grupos de plantas havia frutos distribuídos ao acaso, representados pelos pontos localizados abaixo de linha $\mathrm{x}=\mathrm{y}$ (Figura 3$)$. A agregação foi tanto maior quanto maior a incidência. Esses dados sugerem que a origem do inóculo é localizada e, provavelmente, restrita ao inóculo gerado a partir dos ramos de poda caídos no solo, visto que não se constatou a presença de cancros nos ramos das plantas. A presença de inóculo conidial, disperso pela chuva, deveria refletir-se em padrão altamente agregado de frutos dentro da árvore. Assim, o principal inóculo da safra 2000-2001 deve ter sido composto de ascósporos, que apesar de necessitarem de água para liberação são transportados pelo vento (Sutton, 1981) e caracterizam-se por produzir padrões de doença ao acaso ou ligeiramente agregado.

\section{Sobrevivência e detecção de Botryosphaeria dothidea nos ramos de macieiras no pomar}

Os resultados apresentados na Tabela 4 mostraram que quando ramos sadios oriundos da poda das macieiras permanecem embaixo da copa das plantas, no inicio da

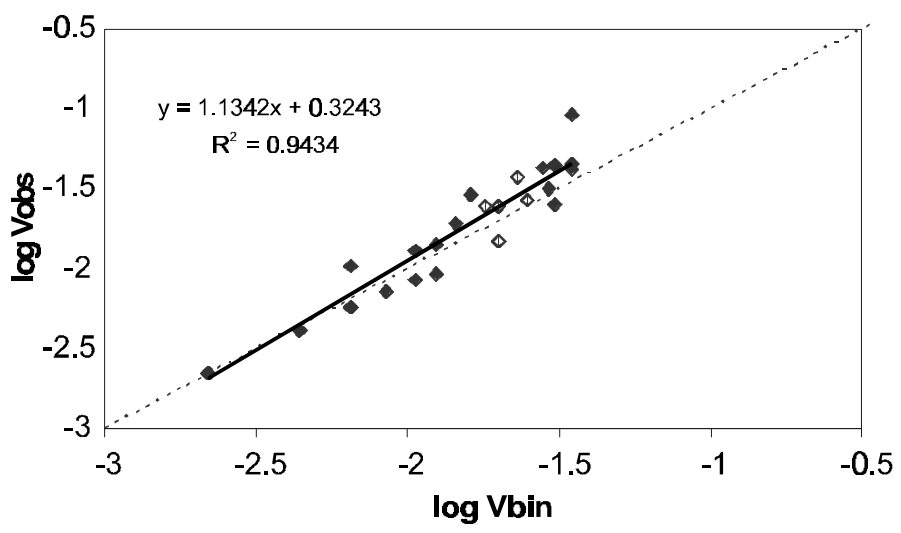

FIG. 3 - Relação entre o logaritmo da variância observada e o logaritmo da variância binomial de frutos de macieira (Malus domestica) com podridão de Botryosphaeria dothidea. Cada ponto representa um grupo de seis plantas nas quais avaliou-se a incidência de frutos doentes em quadrats de cinco frutos. A linha sólida representa a regressão linear dos pontos e linha tracejada representa a situação de aleatoriedade em que a variância binomial é igual à variância observada.

TABELA 4 - Presença de esporos de Botryosphaeria dothidea nos ramos de macieira (Malus domestica) da poda de inverno no ciclo 1998-1999. Vacaria, RS

\begin{tabular}{|c|c|c|c|c|}
\hline \multirow[b]{2}{*}{ Tipo de ramo } & \multicolumn{4}{|c|}{ Presença de esporos nas amostras ${ }^{1}$} \\
\hline & $03 / 02 / 99$ & $25 / 02 / 99$ & $03 / 04 / 99$ & $\begin{array}{c}\text { Freqüîncia de } \\
\text { ramos com } \\
\text { estruturas do } \\
\text { patógeno }(\%)\end{array}$ \\
\hline Grosso & sem & - & + & 19,6 \\
\hline Médio & sem & & + & 21,6 \\
\hline Fino & sem & + & + & 19,6 \\
\hline Total (51) & & & & 60,8 \\
\hline
\end{tabular}

${ }^{1}$ Dados relativos a 17 segmentos em cada grupo ramos analisados 
primavera, ocorre o desenvolvimento neles do inóculo de $B$. dothidea. Na avaliação do material, a produção de inoculo constituído por conídios e ocasionalmente de ascósporos ocorreu somente nas semanas próximas da colheita e o diâmetro dos ramos não afetou a colonização pelo patógeno.

A principal fonte de inóculo de $B$. dothidea, de acordo com a literatura, são os ramos de poda da macieira que permanecem no pomar e onde picnídios e pseudotécios do patógeno se desenvolvem (Drake, 1971; Sutton \& Boyne, 1983). A constatação deste fato, porém, não havia sido relatada no Brasil. Os produtores, por não disporem de informações sobre a ocorrência de condições para a infecção por $B$. dothidea, protegem a cultura durante todo o período. Sugere-se, portanto, a utilização de ramos de poda para monitorar a disponibilidade de inóculo. Esta prática poderá ser útil para apoiar recomendações de um sistema de alerta para a doença visando a racionalização dos tratamentos químicos da cv Fuji durante o verão.

\section{REFERÊNCIAS BIBLIOGRÁFICAS}

BAILEY, J.A., O'CONELL, R.J., PRING, R.J. \& NASH, C. Infection strategies of Colletotrichum species. In: Bailey, J.A. \& Jeger, M.J. (Eds.) Colletotrichum: Biology, pathology and control. Wallingford: CAB International, 1992. pp.88-120.

BIGGS, A.R. Detection of latent infections in apple fruit with paraquat. Plant Disease 79:1062-1067. 1995.

BONETI, J.I.S., RIBEIRO, L.G. \& KATSURAYAMA, Y. Manual de identificação de doenças e pragas da macieira. Florianópolis: Epagri, 1999.

BROWN II, E.A. \& BRITTON, K.O. Botryosphaeria diseases of apple and peach in the Southern United States. Plant Disease 70:480484. 1986.

BROWN, E. A. \& HENDRIX, F. F. Pathogenicity of Botryosphaeria dothidea on apple stems. Phytopathology 71:584-589. 1981.

CAMPBELL, C.L. \& MADDEN, L.V. Introduction to Plant Disease Epidemiology. New York. John Wiley \& Sons. 1990.

DRAKE, C.R. Source and longevity of apple fruit rot inoculum of Botryosphaeria ribis and Physalospora obtusa under orchard condition. Plant Disease Reporter 55:122-126. 1971.

FENNER, A. A rot of apples caused by Botryosphaeria ribis. Phytopathology15:230-234. 1925.

FOKKEMA, N.J. Agrochemicals and the beneficial role of phyllosphere yeasts in disease control. Ecological Bulletins 39:9193. 1988.

FULKERSON, J.F. Botryosphaeria ribis and its relation to a rot of apples Saint Paul: Phytopathology 50:394-398. 1960.
HUGHES, G. \& MADDEN, L.V. Aggregation and incidence of disease. Plant Pathology 41:657-660. 1992.

HUTTON, K.E. \& LEIGH, D.S. Dothiorella canker and died back of apple trees. The Agricultural Gazette 69:192-195. 1958.

JONES, A.L. \& ALDWINCKLE, H.S. (Eds.) Compendium of apple and pear diseases. St. Paul: American Phytopathological Society, 1990. 100p.

KOHN JUNIOR, F.C. \& HENDRIX, F.F. Influence of sugar content and $\mathrm{pH}$ on development of white rot of apples. Plant Disease 67:410412. 1983.

LEWIS, G. D. Botryosphaeria canker and fruit rot of apple in New York. Plant Disease Reporter 40:228. 1956.

LEWIS, G.D. \& SHAY, J.R. Control of summer diseases of apples. Plant Disease Reporter 37:84-87. 1953.

MADDEN, L.V. \& HUGHES, G. Plant disease incidence: distributions, heterogeneity, and temporal analysis. Annual Review of Phytopathology 33:529-564. 1995.

MELZER, R. \& BERTON, O. Incidência de Botryosphaeria berengeriana na cultura da macieira (Malus domestica) no Estado de Santa Catarina, Brasil. Fitopatologia Brasileira 11:891-898. 1986.

PARKER, K.C. \& SUTTON, T.B. Effect of temperature and wetness duration on apple fruit infection and eradicant activity of fungicides against Botryosphaeria dothidea. Plant Disease 77:181-185. 1993a.

PARKER, K.C. \& SUTTON, T.B. Susceptibility of apple fruit to Botryosphaeria dothidea and isolate variation. Plant Disease 77:385389. 1993 b.

PENNOK, W. \& MALDONADO, G. Hot water treatments of mango anthracnose. Journal of Agriculture University of Puerto Rico 46:272- 283. 1962.

PETRI, J.L. Desafios da pesquisa na produção integrada de maçã. In: Reunião Sobre o Sistema de Produção Integrada de Macieira no Brasil, 1., Bento Gonçalves, Anais ... Bento Gonçalves: Embrapa Uva e Vinho, 1998, pp.1-2.

PRUSKY, D., WATTAD, C. \& KOBILER, I. Effect of the ethylene on activation of lesion development from quiescent infections of Colletotrichum gloeosporioides in avocado fruits. Molecular Plant Microbe Interactions 9:864-868. 1996.

SHAY, J.R. \& SITTERLY, W.R. Botryosphaeria canker of apple. Phytopathology 44:505. 1954. (Abstract)

SHEAR, C.L., STEVENS, N.E. \& WILCOX, M.S. Botryosphaeria and Physalospora in the Eastern United States. Mycologia 17:98107. 1925.

SUTTON, T.B. Production and dispersal of ascospores and conidia by Physalospora obtusa and Botryosphaeria dothidea in apple orchards. Phytopathology 71:584-589. 1981.

SUTTON, T.B. \& BOYNE, J.V. Inoculum availability and pathogenic variation of Physalospora obtusa and Botryosphaeria dothidea in apple production in North Carolina. Plant Disease 67:503-506. 1983. 